\title{
A NOTE ON THE TEXTS
}

Extant copies of the titles included here are housed in libraries across the country either as bound pamphlets or in serial newspapers. The most readily available copies of the texts, however, are found in the Wright American Fiction microfilm collection. All of the texts reprinted here derive from the Wright collection housed in the University of New Mexico's Zimmerman Library because it is the most accessible venue for each text but also because the microfilm copies allowed the editors to handle the texts in ways we could not handle originals. Considering the nature of popular fiction, there are certainly variations across publications, especially the ones that first appeared serially and then in pamphlet form, but we have made no effort to establish authoritative texts. Instead, the texts were transcribed from their microfilm form to an electronic document. They have been edited for this collection. All of the original copyright pages and illustrations were expunged, as were the original chapter synopses in Buntline's Magdalena. Some of the chapters of Denison's La Vintresse have been redacted for the sake of space. We did not correct content related to characterization, vernacular, or foreign words or names, but we did standardize the texts to American spelling and punctuation. We silently corrected anomalous misspellings and typographical errors, and we modernized punctuation marks such as quotation marks and dashes. Invariably the transcription process generated textual slips, and while we have made every effort to catch these mistakes, we nonetheless regret any egregious corruptions in our edited reprints. 



\section{Empire}

AND THE LITERATURE OF SENSATION 
